\title{
Online nutrition and T2DM continuing medical education course launched on state-level medical association
}

\section{Kristen K Hicks \\ Peter S Murano}

Texas A\&M University, Department of Nutrition and Food Science, College

Station, TX, USA
Correspondence: Kristen K Hicks Texas A\&M University, 218 Cater Mattil, 2253 TAMU, College Station, TX 77843, USA

Tel +I 480 20I 1924

Email kkhicks।@gmail.com
This article was published in the following Dove Press journal:

Advances in Medical Education and Practice

27 June 2017

Number of times this article has been viewed

Objective: The purpose of this research study was to determine whether a 1-hour online continuing medical education (CME) course focused on nutrition for type 2 diabetes would result in a gain in nutrition knowledge by practicing physicians.

Methods: A practicing physician and dietitian collaborated to develop an online CME course (both webinar and self-study versions) on type 2 diabetes. This 1-hour accredited course was launched through the state-level medical association's education library, available to all physicians.

Results: Physicians ( $n=43$ ) registered for the course, and of those, 31 completed the course in its entirety. A gain in knowledge was found when comparing pre- versus post-test scores related to the online nutrition CME $(P<0.0001)$.

Conclusions: Online CME courses launched via state-level medical associations offer convenient continuing education to assist practicing physicians in addressing patient nutrition and lifestyle concerns related to chronic disease. The present diabetes CME one-credit course allowed physicians to develop basic nutrition care concepts on this topic to assist patients in a better way. Keywords: continuing medical education, CME, online/computer-based education, nutrition education, preventive nutrition and chronic disease, type 2 diabetes

\section{Introduction}

The US healthcare system is transitioning to a more preventive-based approach, of which healthy eating and lifestyle approaches are at the forefront, since nutrition and health behaviors are implicated to impact chronic disease development and progression. The literature has highlighted that poor nutrition contributes to chronic disease, ultimately contributing to morbidity and mortality. ${ }^{1-3}$ A landmark study, EPIC-Norfolk, discovered that individuals with poor health behaviors (low fruit and vegetable intake, lack of physical activity, and tobacco, alcohol use) had over four times greater risk of mortality. ${ }^{4}$ Specific to type 2 diabetes mellitus (T2DM), dietary intake plays a critical role in the management of the disease. Providing dietary and lifestyle education focused on T2DM has resulted in improved self-management and a reduction in both hemoglobin A1c (HbA1c) and 2-hour blood glucose levels. ${ }^{5-7}$

Primary care physicians and their patients can benefit from incorporating basic nutrition and lifestyle focused counseling. However, nutrition education in medical schools is lacking. Physicians acknowledge limited nutrition knowledge and are seek- 
ing opportunities for nutrition education. ${ }^{89}$ Development of nutrition-related continuing medical education (CME) courses has been proposed as a feasible strategy to enhance physician education. Lifestyle-focused CME programs have been shown to have a positive impact on physician knowledge, confidence, and overall counseling behaviors. ${ }^{10,11}$ Various formats, length of CME, and accompanying credits provide versatile offerings for physicians to obtain CME credits. Multicourse CME programs have been shown to be successful in knowledge gain and practical application of material into practice. ${ }^{12,13}$ The American College of Lifestyle Medicine has a basic and advanced $30 \mathrm{CME}$ Lifestyle Medicine Training Curriculum which encompasses several key competencies to integrate lifestyle medicine into practice. The "Healthy Kitchens, Healthy Lives" CME conference is a live 4-day program including medical and culinary education. ${ }^{14}$ Programs that encompass several CME credits, as part of a comprehensive program, are becoming more prevalent. Although multicourse CME programs focused on nutrition and lifestyle are important, other practical course topics such as billing, risk management, compliance, and practice operations often take precedence.

Due to a variety of factors, including physician request, concise and focused CME courses have been suggested. Regarding education focused specifically on nutrition care for T2DM, unfortunately limited independent one-credit CME courses are available. A recent publication described the need for CME focused on T2DM, with the inclusion of practical application tips. ${ }^{15}$ There is a documented need and corresponding positive impact when nutrition and lifestyle counseling are delivered to patients with T2DM. ${ }^{6,16-19}$ To begin to address this need, a few CME courses focused on nutrition and treatment of T2DM have been implemented. An independent multiplatform CME course (live and online) focused on T2DM resulted in physicians improving their knowledge and assisting with reducing patient $\mathrm{HbA} 1 \mathrm{c} .{ }^{20}$ Preliminary analysis from video-based education CME courses on diabetes care showed improvements in knowledge and competence for diabetes management. ${ }^{21}$ These independent programs, provided through independent websites, represent a beginning. It remains to be seen whether nationwide interest in such independent courses by physicians will be generated.

Due to the limited single-course offerings regarding nutrition and T2DM, the authors created an online CME focused on T2DM. It was hypothesized that providing a diabetes-focused CME course, launched in collaboration with state-level medical associations, would have a positive impact on physicians' knowledge regarding diabetic patient care.

\section{Methods}

\section{Study setting}

An online CME course was jointly developed by a physician, a dietitian, and a researcher focused on nutrition education delivery to physicians. This collaborative effort allowed practicing clinicians to work together, as they would in healthcare practice, to develop a course that could be utilized as a learning tool to help patients. Each creator has an extensive nutrition background and all focus on nutrition for prevention medicine, whether it be in research or in clinical practice. For the course "Frontiers in Type 2 Diabetes: The Role of Nutrition in Health", the target learning audience was Texas physicians, of all practice specialties. The course was launched by the Texas Medical Association in January 2016 and was disseminated via the InReach ${ }^{\odot}$ sharing network, and it was subsequently accessed by the Oregon Medical Association and South Carolina Medical Association.

The educational activity was designed to measure the amount of knowledge gained on the basis of information provided through the course. Physicians who participated were billed accordingly to the state-level medical association for CME credits. Courses were accredited by the Accreditation Council for Continuing Medical Education for one AMA PRA Category 1 Credit $^{\mathrm{TM}}$ or one Ethics Credit. Course development was purposely created to be different than any current nutrition-focused CME offerings that the authors were aware of. The goal was to offer the most relevant and up-to-date content on the topic of T2DM and disseminate applied approaches to provide nutrition counseling. The CME curriculum was designed using the Attention, Relevance, Confidence, Satisfaction (ARCS) Model of Motivation, an eLearning technique used in online course development, shown to improve knowledge. ${ }^{22}$ This model was selected due to the emphasis on practical application of nutrition care to patients, a core concept in the course. Unlike other CME courses, this had the following four main objectives:

1) Highlight national nutrition recommendations;

2) Introduce and discuss basic nutrition concepts;

3) "How-to" provide nutrition care for patients including practical approaches and motivational interviewing techniques;

4) Utilizing a collaborative healthcare approach with billing codes for reimbursement.

The webinar and self-study module included the following: background information on T2DM and specific learning objectives; complications associated with T2DM; recommendations for interventions according to professional 
health associations; the role of the physician in screening, diagnosis, treatment, and prevention of T2DM; two case studies for practice; lifestyle recommendations and medical nutrition therapy; implementing best practice techniques (motivational interviewing techniques; nutrition awareness in the office setting); SMART goal setting (goals that are specific, measurable, attainable, relevant, and time bound); working with patients in collaboration with registered dietitians; and overview of billing codes according to the new International Classification of Diseases Tenth Revision billing system.

\section{Data collection and analysis}

Course participants accessed course content that included demographic disclosure, pretest, T2DM course content, and post-test. Demographic characteristics included gender, zip code of practice, credentials, practice specialty, and years in practicing medicine. The online activity was accompanied with a 16 multiple choice question test bank in which ten questions at random were generated for the pretest and post-test. Questions focused on basic nutrition knowledge, nutrition-related terms, and current nutrition recommendations, relative to T2DM; all content that was emphasized in the course. The test bank was created by the healthcare professionals who created the course, to address the competencies of the learning objectives. From January 2016 to December 2016, physicians had the option of selecting either a 42-minute online webinar or a 9-page self-study PDF module, as means of participating in the study.

This study was approved by the Texas A\&M University Institutional Review Board (IRB \# IRB2015-0779D).

\section{Results}

\section{Participant demographics}

Physicians who participated in our study provided select demographic information including credentials, gender, years in practice, zip code of practice, and practice specialty (Table 1; Figure 1).

\section{Pretest and post-test scores}

A score of $70 \%$ or better was required to "pass" our CME for credit, and $93 \%$ of physicians achieved this score. Two physicians showed no increase in test scores comparing pre- and post-test and also did not achieve a passing score of $70 \%$ on the post-test to obtain credit. The use of a paired $t$-test among pre- and post-test scores per user revealed a significant gain of knowledge $(P<0.0001)$ (Figure 2$)$. No data to distinctly

Table I Physician demographics

\begin{tabular}{ll}
\hline Category & Description (n, \% participants) \\
\hline Credentials & MD $(40,93)$ \\
Gender & DO $(3,7)$ \\
& Male $(24,56)$ \\
Years in practice & $1-5(8,19)$ \\
$6-10(4,9)$ \\
II-15 $(6,14)$ \\
$16-20(5,12)$ \\
$2 I-25(7,16)$ \\
$26+(13,30)$ \\
State of residence & Texas $(38,88)$ \\
& New Mexico $(2,5)$ \\
& Missouri $(I, 2)$ \\
& Alabama $(1,2)$ \\
& Wisconsin $(I, 2)$ \\
\hline
\end{tabular}

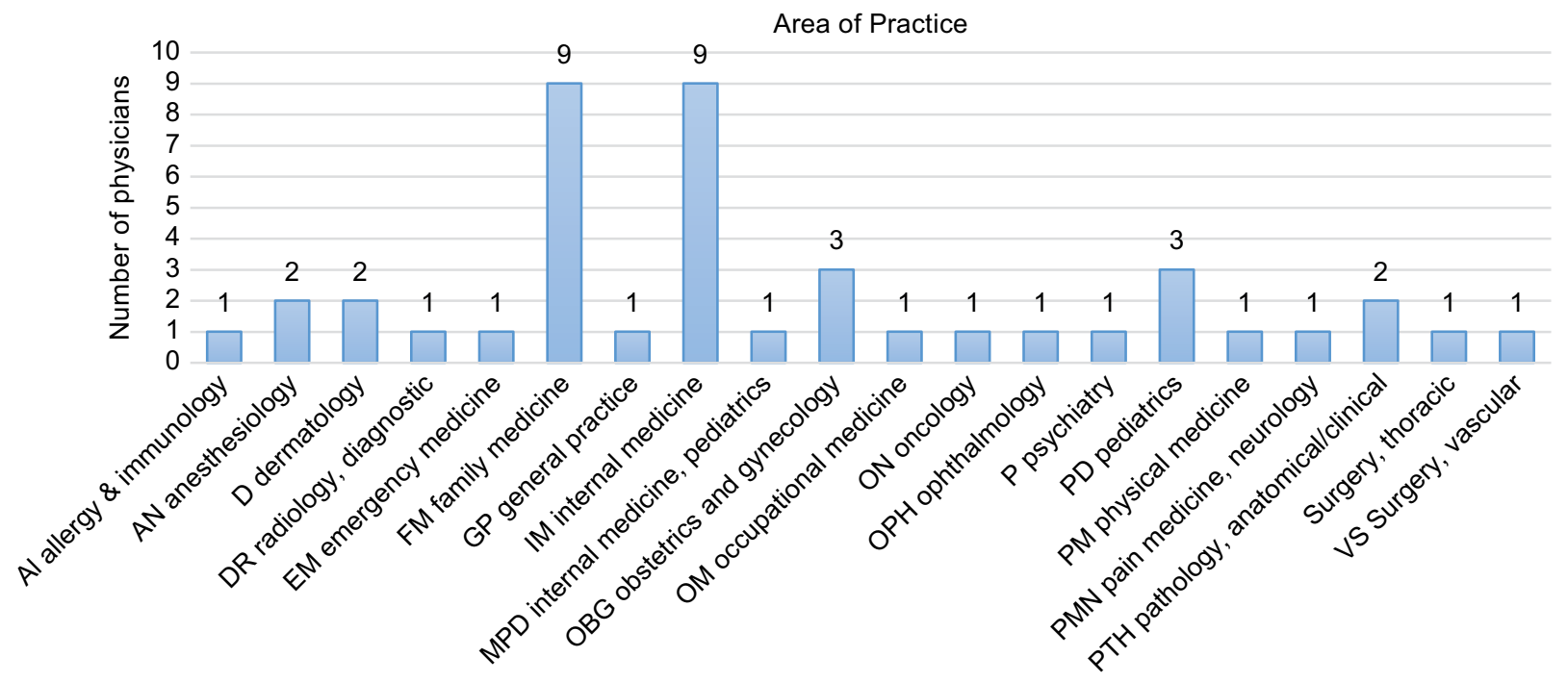

Figure I Various Areas of Practice specialties. 


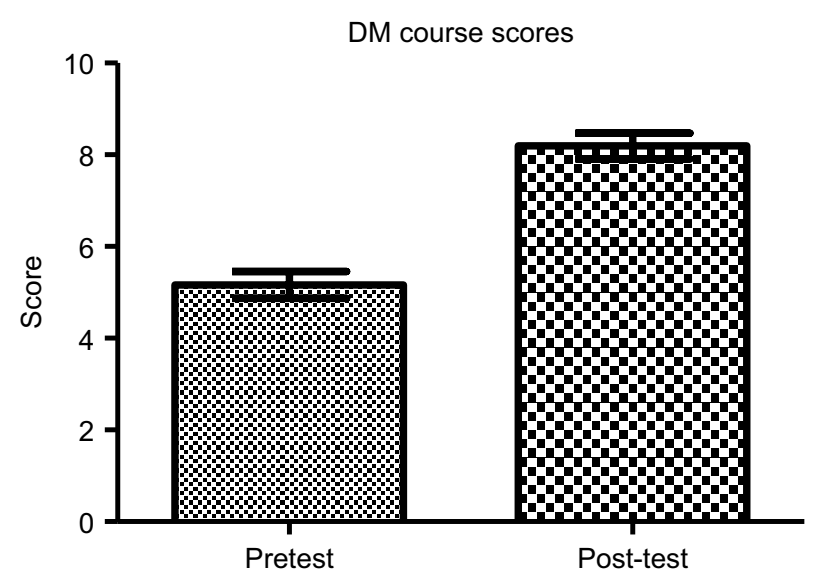

Figure 2 Pretest versus post-test evaluation. Abbreviation: DM, diabetes mellitus.

separate self-study versus webinar-associated test scores were available to us to analyze any differences.

A comparison of pre- versus post-test scores showed that recognition of the prevalence of T2DM nationwide increased from $21 \%$ to $96 \%$, respectively. After the course, a majority $(92 \%)$ of physicians were able to accurately recognize that carbohydrates were an important macronutrient to monitor for a patient with T2DM. The overall goal of medical nutrition therapy was correctly answered by all physicians in the post-test.

\section{Ratings}

Physicians who completed the course were required to provide a rating of the course out of five stars. The participants who completed all components of the course provided a rating of overall course content and delivery. Rating breakdown included: 5 stars (19), 4 stars (11), and 3 stars (1) with no ratings of a 2 or 1 star. In addition, a brief feedback was provided as a comment such as "will incorporate into my practice", "good content", and "it has lots of useful information".

\section{Discussion}

We believe that this research study is the first to report an increase in nutrition knowledge of physicians by completing a single online nutrition-focused CME on T2DM launched on the state-level education platform. Physicians who completed the course improved scores significantly, indicating a gain in knowledge based on learning from course materials. These results are consistent with previous research that has demonstrated the overall efficacy of CME courses on course outcomes. ${ }^{14,20,21,23,24}$ A study assessing over $600 \mathrm{CME}$ programs found that online activities were more effective to simple enduring materials, multimedia inclusion was comparable to live activities. ${ }^{25}$ These findings have important implications for CME developers as they develop and launch new CME courses. A unique feature in our online course was incorporation of a multimedia-based component of two separate case studies. Published research demonstrates that online CME courses that include multimedia activities are effective. ${ }^{26}$

It is suggested that through course content delivery such as we have demonstrated, enhanced physician-patient interactions that more successfully address T2DM may occur. This is important because patients diagnosed with T2DM are at increased risk of comorbidities and mortality. Integration of lifestyle counseling with T2DM patients has resulted in improvements in weight, HbA1c, and overall lifestyle patterns. ${ }^{18,20,27,28}$ Noncommunicable disease can be prevented and/or managed with improvements in physician-patient interactions focused on diet and lifestyle.

\section{Limitations}

This research study had several limitations. This course was available only through a few state-level medical associations, limiting physician participant awareness and access. Second, since this course was fee-based (\$29 member and $\$ 79$ nonmember) within Texas, it is likely that the physicians who registered for the course had higher inherent interest in learning nutrition care related to diabetes. We also could not report what the overall response rate was among physicians since we did not have access to that data. The fact that the number of participants was limited, and that they were mainly Texas physicians, suggests that there was no true representativeness in our participant sample. This study did not obtain data on the actual implementation of course content into practice. There is a need for CME evaluations to include long-term follow-up as part of studies. It may be a limitation that the course cannot be considered truly comprehensive on account of its brevity. The purpose of the course is to instill basic concepts of nutrition and simplistic methods to integrate nutrition into counseling; this is not a replacement for a multicourse nutrition education program that would provide a more comprehensive outlook on nutrition and T2DM.

\section{Summary}

Results from this pilot study indicate that nutrition-focused CME courses on a state-level medical association offer a feasible option for physicians to learn and incorporate nutrition topics into their practices. There is a need for physicians to increase nutrition knowledge related to chronic disease prevention and development, and the inclusion of a 1-hour 
course can begin addressing this need. A call for CME that includes a practical component, such as interactive case studies, will support physicians seeking to integrate new knowledge into their practices. ${ }^{29}$

This research study demonstrated that online CME courses launched on state-level medical association platforms improved subject matter knowledge. Ultimately, physicians who couple knowledge basics with practical application tools may more successfully integrate these into their practices. Since the rate of T2DM prevalence is increasing, there is no better time to create targeted nutrition offerings to enhance physician knowledge and effectiveness.

\section{Lessons for practice}

Nutrition-focused CME courses available on the state-level medical association platform are viable opportunities to disseminate nutrition information and improve contentspecific nutrition knowledge of practicing physicians.

\section{Disclosure}

The authors report no conflicts of interest in this work.

\section{References}

1. Morris NP. The neglect of nutrition in medical education: a firsthand look. JAMA Intern Med. 2014;174(6):841-842.

2. Hivert MF, Arena R, Forman DE, et al. Medical training to achieve competency in lifestyle counseling: an essential foundation for prevention and treatment of cardiovascular diseases and other chronic medical conditions: a scientific statement from the American Heart Association. Circulation. 2016;134(15):e308-e327.

3. Pronk NP, Remington, P.L. Combined diet and physical activity promotion programs for prevention of diabetes: community preventive services task force recommendation statement. Ann Intern Med. 2015;163(6):465-468.

4. Khaw KT, Wareham N, Bingham S, Welch A, Luben RN, Day N. Combined Impact of health behaviours and mortality in men and women: the EPIC-Norfolk prospective population study. PLoS Med. 2008;5(1):e12.

5. Breen C, Ryan M, Gibney MJ, O'Shea D. Diabetes-related nutrition knowledge and dietary intake among adults with type 2 diabetes. $\mathrm{Br}$ Nutr. 2015;114(3):439-447.

6. Baum HB, Cagliero E, Berry CA, Mencia WA, Stowell SA, Miller SC. Continuing improvement in type 2 diabetes care through performance-based evaluations. J Prim Care Community Health. 2014;5(2): 107-111.

7. Sun Y, You W, Almeida F, Estabrooks P, Davy B. The effectiveness and cost of lifestyle interventions including nutrition education for diabetes prevention: a systematic review and meta-analysis. J Acad Nutr Diet. 2017;117(3):404-421.e436.

8. Kristen Hicks K, Murano PS. Physician perspectives on nutrition counseling and nutrition focused continuing medical education in Texas. Social Med. 2016;10(3):1-7.

9. Wynn K, Trudeau JD, Taunton K, Gowans M, Scott I. Nutrition in primary care: current practices, attitudes and barriers. Can Fam Physician. 2010;26(3):e109-e116.
10. Beno L, Hinchman J, Trowbridge F. Design and implementation of training to improve management of pediatric overweight. J Contin Educ Health Prof. 2005;25(4):248-258.

11. Kahn RF. Continuing medical education in nutrition. Am J Clin Nutr. 2006(83 Suppl):981S-984S.

12. Polak R, Shani M, Dacey M, Tzuk-Onn A, Dagan I, Malatskey L. Family physicians prescribing lifestyle medicine: feasibility of a national training Programme. Postgrad Med J. 2016;92(1088):312-317.

13. Allison JJ, Kiefe CI, Wall T, et al. Multicomponent internet continuing medical education to promote chlamydia screening. Am J Prev Med. 2005;28(3):285-290.

14. Eisenberg D, Miller A, McManus K, et al. Altering nutrition-related behaviors of healthcare professionals through CME involving nutrition experts and chefs. BMC Complement Altern Med. 2012; 12(Suppl 1):O17.

15. Beaser RS, Brown JA. Preventive intervention in diabetes: a new model for continuing medical education. Am J Prev Med. 2013; 44(4 Suppl 4):S394-S399.

16. Azar KMJ, Chung S, Wang EJ, Zhao B, Linde RB, Lederer J, Palaniappan LP. Impact of education on weight in newly diagnosed type 2 diabetes: every little bit helps. PLos One. 2015;10(6):e0129348.

17. Aguiar EJ, Morgan PJ, Collins CE, Plotnikoff RC, Young MD, Callister R. The PULSE (Prevention Using LifeStyle Education) trial protocol: a randomised controlled trial of a type 2 diabetes prevention programme for men. Contemp Clin Trials. 2014;39(1):132-144.

18. Linmans JJ, Van Rossem C, Knottnerus JA, Spigt M. Exploring the process when developing a lifestyle intervention in primary care for type 2 diabetes: a longitudinal process evaluation. Public Health. 2015;129(1): $52-59$.

19. Ball L, Davmor R, Leveritt M, Desbrow B, Ehrlich C, Chaboyer W. Understanding the nutrition care needs of patients newly diagnosed with type 2 diabetes: a need for open communication and patient-focussed consultations. Aust J Prim Health. Epub 2015 Oct 5.

20. Lee B, Trence D, Inzucchi S, et al. Improving type 2 diabetes patient health outcomes with individualized continuing medical education for primary care. Diabetes Ther. 2016;7(3):473-481.

21. Larkin A, Healy C, Le A. SUN 757: Type 2 diabetes quality improvement CME: impact on physician knowledge. In Endocrine Society Annual Meeting; April 2016; Boston, MA.

22. Wongwiwatthananukit S, Popovich NG. Applying the ARCS model of motivational design to pharmaceutical education. Am J Pharm Educ. 2000;64(2):188.

23. Dacey M, Arnstein F, Kennedy MA, Wolfe J, Phillips EM. The impact of lifestyle medicine continuing education on provider knowledge, attitudes, and counseling behaviors. Med Teach. 2013;35(5):1149-1156.

24. Sargeant J, Valli M, Ferrier S, MacLeod H. Lifestyle counseling in primary care: opportunities and challenges for changing practice. Medical Teacher. 2008;30(2):185-191.

25. Salinas GD. CME Effectiveness: utilizing outcomes assessments of $600+$ CME Programs to evaluate the association between format and effectiveness. J Contin Educ Health Prof. 2015;35(Suppl 1): S38-S39.

26. McFadden P, Crim, A. Comparison of the effectiveness of interactive didactic lecture versus online simulation-based CME programs directed at improving the diagnostic capabilities of primary care practitioners. J Contin Educ Health Prof. 2016;36(1):32-37.

27. Wing RR, Bolin P, Brancati FL, et al. Cardiovascular effects of intensive lifestyle intervention in type 2 diabetes. $N$ Engl J Med. 2013;369(2): $145-154$.

28. Galaviz KI, Narayan KMV, Lobelo F, Weber MB. Lifestyle and the prevention of type 2 diabetes: a status report. Am J Lifestyle Med. 2015: $1-17$.

29. Al-Azri H, Ratnapalan, Savithiri. Problem-based learning in continuing medical education. Can Fam Physician. 2014;60:157-165. 
Advances in Medical Education and Practice

Dovepress

\section{Publish your work in this journal}

Advances in Medical Education and Practice is an international, peerreviewed, open access journal that aims to present and publish research on Medical Education covering medical, dental, nursing and allied health care professional education. The journal covers undergraduate education, postgraduate training and continuing medical education

including emerging trends and innovative models linking education, research, and health care services. The manuscript management system is completely online and includes a very quick and fair peer-review system. Visit http://www.dovepress.com/testimonials.php to read real quotes from published authors.

Submit your manuscript here: http://www.dovepress.com/advances-in-medical-education-and-practice-journal 